\title{
Variation in evacuation rates of different foods skew estimates of diet in the western rock lobster, Panulirus cygnus.
}

\author{
Kris Waddington
}

5 M090 School of Plant Biology

The University of Western Australia

35 Stirling Highway

Crawley 6009.

Western Australia

10 Ph: +61864887919

Fax: +61 864881001

Email: krisw@cyllene.uwa.edu.au

\section{Abstract}

Knowledge regarding differences in evacuation rates of diet items from a consumers' stomach is important when using gut content analysis to quantify consumer diet. Evacuation rates of three diet items (pilchards, crabs and coralline algae) from the foreguts of western rock lobsters (Panulirus cygnus) were compared in aquaria. To

20 determine evacuation rates, lobsters were allowed to consume offered food during a 90 minute feeding period, before being sacrificed at 4, 6, 8, 10 and 12 hours after the feeding period concluded. Diet items differed in their rate of evacuation from lobster foreguts with coralline algae evacuated most rapidly, followed by crabs, then pilchards. Evacuation of crabs and pilchards was still not complete 12 hours after the feeding period

25 concluded. Food not evacuated after 12 hours predominantly consisted of hard components of lobster diet, indicating it is these components that account for slower evacuation. Observed variation in evacuation rates between diet items may skew results of studies that use gut content analysis to quantify diet of western rock lobsters.

\section{$30 \quad$ Keywords}


Foregut; evacuation rate; gut content analysis; dietary composition.

\section{Introduction}

Identification of the contents of a consumers' gut is a simple and effective way of assessing its diet, with the composition of the consumers' gut related to food ingested prior to evacuation from the gut (Williams 1981; Cristo 2001). An understanding of gut evacuation rates of different diet items is important when using gut content analysis to

40 quantify dietary composition of a consumer (Hill 1976; Choy 1986). Differences in evacuation rates of diet items may influence results from gut content analysis - diet items that are quickly evacuated are underestimated relative to diet items that are evacuated more slowly (Sarda and Valladares 1990).

45 Studies of a number of decapod crustaceans have demonstrated that evacuation rate of diet items from the foregut occurs at different rates (Hill 1976; Choy 1986; Sarda and Valadares 1990). These studies showed that foregut evacuation rates are slower for diet items with hard components compared to diet items with no hard components. The only previous study investigating foregut clearance rates of western rock lobsters (Panulirus

50 cygnus) did not consider diet items with hard body parts (Joll 1982), and crustaceans and fish have been shown to be important lobster diet items (Joll and Phillips 1984; Jernakoff et al. 1993; Waddington, unpublished data). I determined evacuation rates of these diet items from the foreguts of western rock lobsters. Crustaceans and fish have hard body components that may be evacuated more slowly from lobster foreguts relative to

55 evacuation of diet items previously tested.

I investigated evacuation rates of three diet items (pilchards, crabs and coralline algae) from the foregut of western rock lobsters. I tested the null hypothesis that there is no difference in evacuation rates between diet items.

\section{Materials and Methods}


Western rock lobsters (70-76 $\mathrm{mm}$ carapace length) were trapped from Marmion Lagoon $\left(31^{\circ} 44^{\prime} \mathrm{S}, 115^{\circ} 40^{\prime} \mathrm{E}\right)$. Prior to experiment commencing, lobsters were kept in 2 circular

65 tanks, $1.0 \mathrm{~m}$ diameter $\times 0.8 \mathrm{~m}$ deep for 7 days to acclimate. During this time experimental animals were provided with a brick and PVC shelter and fed mussels, (Mytilus edulis (L.)) to excess. After acclimating for one week, feeding was ceased for one week to ensure lobsters consumed offered food during experimentation.

70 The experiment was performed over two consecutive nights during July 2007. A total of 15 lobsters were used each day. On the day prior to experimentation, lobsters were randomly allocated to one of 15 aquaria $30 \mathrm{~cm} \times 40 \mathrm{~cm} \times 40 \mathrm{~cm}$. A plastic mesh shelter was provided to each lobster. Flow rates of the tanks were $18 \mathrm{~L}^{\mathrm{h} \mathrm{hr}^{-1}}$. Lighting was ambient (approximately 11 hours light/ 13 hours dark) as was water temperature $\left(16^{\circ} \mathrm{C}\right)$.

75 Ambient water temperatures were chosen so that results are applicable when correcting dietary composition data from wild caught lobsters. An excess amount of food was blotted dry, weighed $( \pm 0.01 \mathrm{~g})$, then fed to experimental lobsters 1.5 hours prior to sunrise. Lobsters were then allowed to feed undisturbed until sunrise. This feeding period was chosen as spiny lobsters have been shown to be nocturnal foragers (Jernakoff et al.

80 1987), with a peak in feeding activity just prior to sunrise (Kanciruk and Herrnkind 1973). At sunrise, uneaten food was first removed by hand, then by siphoning water through a $125 \mu \mathrm{m}$ sieve. Food removed was blotted dry and reweighed $( \pm 0.01 \mathrm{~g})$. As no food was able to escape the tank during the feeding period, and this species has not been observed to regurgitate food, the difference in the amount of food added to and removed

85 from the tank was assumed to be the quantity of food ingested by the lobsters. Food offered to the pilchards were Australian pilchards (Sardinops sagax Jenyns) (WA Bait Supply, O’Connor, Western Australia), the foliose coralline algae (Metagoniolithon stelliferum (Lamarck)) collected from Marmion lagoon ( $\left.31^{\circ} 44^{\prime} \mathrm{S}, 115^{\circ} 40^{\prime} \mathrm{E}\right)$, and brachyuran crabs (Cyclograpsus audouinii Edwards) collected from Ocean Reef Harbour

$90\left(31^{\circ} 45^{\prime} \mathrm{S}, 115^{\circ} 43^{\prime} \mathrm{E}\right)$. Pilchards and crabs have been observed to be important lobster diet items (Waddington, unpublished data). M. stelliferum has been shown to be an important component of lobster diet (Joll and Phillips 1984; Edgar 1990; Jernakoff et al. 
1993), and has previously been used in gut clearance experiments (Joll 1982) allowing comparison of evacuation rates between studies.

95

Two lobsters fed each diet were sacrificed at 4, 6, 8, 10, 12 hours after the feeding period concluded (hereon referred to as time "post feeding"). When sacrificing, lobsters were immersed in an ice-slurry to induce a chill coma, before having their foreguts removed by dissection. Food in the foregut was removed, blotted dry and weighed to derive a measure

100 of food remaining at each time post feeding.

Food ingested by a lobster passes through the esophagus and into the cardiac stomach (termed the foregut in this study). The cardiac stomach is a muscular chamber with a thick, chitinous lining (Gray 1992). From the cardiac stomach, food passes through the

105 gastric mill into the pyloric sac where it is diverted back to the gastric mill, to the intestine or to the hepatopancreas (Gray 1992). In this study we examine the rate of evacuation of food from the cardiac stomach/foregut of the lobster. Food that had passed through the gastric mill was considered to be evacuated in this study and food remaining refers to the amount of ingested food remaining in lobster foreguts after each time period.

110 "Evacuation rate" refers to the rate at which this ingested food is evacuated from lobster foreguts.

\section{Data analysis}

Amount of ingested food remaining in lobster foreguts was calculated for each time post

115 feeding (4, 6, 8, 10, 12 hours) and for each diet type fed to the lobsters. Amount of food remaining was then expressed as the proportion of the initial amount ingested. Gastric evacuation followed an exponential equation of the type - from Sarda and Valladares (1990):

$120 \quad \mathrm{~W}_{\mathrm{t}}=\mathrm{W}_{\mathrm{o}} \mathrm{e}^{\mathrm{Rt}}$, 
where $\mathrm{W}_{\mathrm{t}}=$ weight of stomach contents at time $\mathrm{t}, \mathrm{A}_{\mathrm{o}}=$ weight of food ingested during the feeding period, $\mathrm{R}=$ instantaneous evacuation rate, and $\mathrm{t}=$ time in hours since the conclusion of the feeding period.

125

Prior to analysis, data were checked for homogeneity of variance using Bartlett's test (Zar 1999). Differences in proportion of ingested food remaining in lobster foreguts were tested using two-way Analysis of Variance (ANOVA), testing the factors diet (fixed, 3 levels) and time (random, 5 levels, crossed with diet). Where differences were observed,

130 these were assessed using post-hoc Tukey tests. Amount of each diet item ingested by the lobsters were also compared using one way ANOVA.

Amount of ingested food remaining in lobster foreguts was calculated for each time post feeding $(4,6,8,10,12$ hours) and for each diet type fed to the lobsters. Amount of food

135 remaining was then expressed as the proportion of food ingested. Differences in proportion of ingested food remaining since feeding concluded were compared using two-way ANOVA. Where significant differences were observed, Tukey tests were used to identify which groups significantly differed. Rate of food evacuation was determined from the difference in the amount of food present at the end of each time period and is

140 expressed as g. $\mathrm{hr}^{-1}$ for each time period. Differences in rates of evacuation of different diet items between time periods were compared using two-way ANOVA and Tukey tests. Amount of each diet item ingested by lobsters were also compared using one-way ANOVA and Tukey tests.

\section{Results}

The proportion of ingested food remaining in lobster foreguts at time $t$ after feeding can be expressed by the following regression equations:

Pilchards: $\mathrm{W}_{\mathrm{t}}=\mathrm{e}^{-0.063 \mathrm{t}}, \mathrm{r}^{2}=0.94$,

150 Crabs: $\mathrm{W}_{\mathrm{t}}=\mathrm{e}^{-0.12 \mathrm{t}}, \mathrm{r}^{2}=0.95$,

Coralline algae: $\mathrm{W}_{\mathrm{t}}=\mathrm{e}^{-0.905 \mathrm{t}}, \mathrm{r}^{2}=0.86$ 
The instantaneous rate of evacuation $(\mathrm{R})$ for coralline algae $(-0.91)$ exceeded the rate of evacuation of crab (-0.12), and pilchard (-0.06) (Fig. 1).

155 Data were found to have homogenous variance $(\mathrm{p}=1.00)$ no transformation of raw data was required prior to analysis. The amount of food remaining in the foregut of lobsters was dependant on both diet type and time since conclusion of the feeding period (Table 1). A significant diet $\times$ time interaction was also observed (Table 1), indicating the proportion of each food type remaining in lobster guts was not constant at each time post-

160 feeding, likely owing to observed differences in evacuation rates between different diet items.

Proportion of pilchards remaining were not significantly different to proportion of crabs remaining after four $(\mathrm{p}=0.45)$ and six hours post-feeding $(\mathrm{p}<0.69)$, but proportion of

165 pilchards and crabs differed to proportion of coralline algae remaining during these times $(\mathrm{p}<0.001)$. After six hours post feeding, all diets differed significantly in proportion of ingested food remaining $(\mathrm{p}<0.05)$.

Differences in the absolute amount of food ingested were detected using one-way

170 ANOVA (Table 2). Post hoc Tukey tests showed that lobsters offered pilchards ingested significantly more food (mean $6.40 \pm$ se 0.38 ) than those offered either crabs or algae $(\mathrm{p}<0.05)$. No significant differences were detected between the amount of crabs $(4.13 \pm$ $0.53)$ or coralline algae $(2.10 \pm 1.04)$ ingested by lobsters $(\mathrm{p}<0.01)$.

175 Examination of foreguts of lobsters fed crabs sacrificed 12 hours post feeding showed matter that had not been evacuated consisted of hard exoskeleton. All flesh and connective tissue had been evacuated. The foreguts of lobsters fed pilchards sacrificed 12 hours post feeding had predominantly bones and scales present in their foreguts as well as a small amount of flesh and muscle tissue. Extrapolation of regression equations indicate

180 that approximately $22.2 \%$ of ingested pilchards and $5.5 \%$ of ingested crabs will remain in lobster foreguts 24 hours after the conclusion of the feeding period. Evacuation of $99 \%$ of 
ingested crabs was estimated to occur 38 hours after feeding period concluded while it was estimated to take $60+$ for $99 \%$ of ingested pilchards to be evacuated.

\section{Discussion}

Diet items were determined to evacuate from the foreguts of western rock lobsters at different rates. Thus, the null hypothesis that there is no difference in foregut evacuation rates of the three diet items is rejected. Evacuation of diet items also occurred

190 significantly slower than evacuation rates previously reported for this species (Joll 1982). Complete evacuation of foods from western rock lobster foreguts has previously been reported to occur 4-6 hours after the feeding period concluded (Joll 1982).

Instantaneous rate of evacuation was observed to differ between diet items with 195 evacuation of coralline algae fastest (-0.91), followed by crabs (-0.12), then pilchards (0.06). These results are in accordance with the findings of Sarda and Valladares (1990) who determined that diet type affects evacuation rates. Rate of crab and pilchard evacuation from this study are comparable with evacuation rates reported for other decapod crustaceans. Sarda and Valladares (1990) reported instantaneous rates of

200 evacuation (R) of between -0.0026 and $-0.0056 \mathrm{hr}^{-1}$ for the Norwegian lobster, Nephrops norvegicus, while in a separate study Cristo (2001) determined R between - 0.177 and $0.172 \mathrm{hr}^{-1}$ for $N$. norvegicus. Choy (1986) determined R between -0.0968 and $-0.1473 \mathrm{hr}^{-1}$ for the crabs Liocarcinus puber and Liocarcinus holsatus. Evacuation of coralline algae from lobster foreguts occurred significantly faster than rates reported in the literature,

205 likely relating to the small amount of coralline algae consumed by the lobsters during the feeding period - lobsters are largely indifferent to coralline algae as a diet item (Joll 1982). Evacuation of food from the stomach of the fish, Pleuronectes platessa has similarly been demonstrated to be dependant upon amount of food consumed (Jobling and Davies 1979).

Evacuation of diet items from the foreguts of western rock lobsters occurred significantly slower than rates previously reported for this species (Joll 1982). Pilchards and crabs 
were present in lobster foreguts 12 hours post-feeding with extrapolation of observed evacuation rates indicating crabs and pilchards will be detected in lobster foreguts at least

21524 hours after the feeding period concluded. Slower evacuation rates in the current study relative to the study of Joll (1982) likely relate to lower water temperatures in the current study $\left(16^{\circ} \mathrm{C} v s .25^{\circ} \mathrm{C}\right)$. Temperature has previously been identified as the most important factor affecting evacuation rates amongst copepods and fish (Jobling and Davies 1979; Dam and Peterson 1988), and has also been shown to affect gut clearance rates for the

220 Portunid crab, Ovalipes catharus (Haddon and Wear 1987). A decrease in water temperature (from $11^{\circ} \mathrm{C}$ to $9^{\circ} \mathrm{C}$ ) led to slower evacuation (from 11 to 18 hours) of food items from foreguts of the Portunid crab (Haddon and Wear 1987). Thus differences in water temperature between the current study and that of Joll (1982) are sufficient to explain observed differences in evacuation rates.

Remnants of food persisting in lobster foreguts at the conclusion of the experimental time (12 hours post feeding period) predominantly consisted of hard components of the diet fed to the lobsters, indicating these items are evacuated from lobster foreguts more slowly than softer components of lobster dietary items. Slower evacuation of hard dietary

230 components relative to soft dietary components has previously been observed for crabs (Hill 1976; Choy 1986), and for the lobster Nephrops norvegicus (Sarda and Valladares 1990). These studies showed that it is common for hard components of the diet to be present 2-3 days after feeding ceased. Similar evacuation times are feasible upon extrapolation of data from the current study.

Variation in evacuation rates of different diet items from lobster foreguts have significant implications for those studies that use foregut composition as a proxy for dietary composition. An underlying assumption when using gut content analysis for the analysis of dietary composition is that composition of diet items in lobster foreguts represents the 240 composition of diet items consumed (eg. Joll and Phillips 1984; Edgar 1990). Variation in evacuation of diet items from lobster foreguts means lobster foregut composition may not represent lobster dietary composition. Since evacuation rates differ with diet type, 
researchers using gut content analysis should correct for variable evacuation rates when calculating consumer dietary composition.

\section{Conclusions}

The current study has demonstrated that evacuation rates of dietary items from the foregut of the spiny lobster species, Panulirus cygnus are variable. Further, foregut

250 evacuation rates observed in this study are slower than rates previously reported for this species, most likely relating to differences in water temperature. Studies that use gut content analysis to estimate dietary composition of western rock lobsters should recognise diet type and temperature as factors that may skew estimates of dietary composition.

\section{Acknowledgements}

I thank Andrew Tennyson and Mathew and Lucas Vanderklift for help collecting diet items. I also thank Mark Rossbach for helping with lobster collection. Mathew

260 Vanderklift and Diana Walker provided helpful comments on an earlier version of this manuscript. Funding for this study was provided by the School of Plant Biology at the University of Western Australia. All procedures were approved by the animal ethics committee at The University of Western Australia (Approval number RA/3/100/478), and authorized under state government permits. 


\section{References}

Choy, S. C. (1986). Natural diet and feeding habits of the crabs Liocarcinus puber and $L$.

270 holsatus (Decapoda, Brachyura, Portunidae). Marine Ecology Progress Series 31, 87-99.

Dam, H. G., and Peterson, W. T. (1988). The effect of temperature on the gut clearance rates of planktonic copepods. Journal of Experimental Marine Biology and Ecology 123, $1-14$.

275

Cristo, M. (2001). Gut evacuation rates in Nephrops norvegicus (L., 1758): laboratory and field estimates. Scientia Marina 65, 341-346.

Edgar, G. J. (1990). Predator-prey interactions in seagrass beds. I. The influence of 280 macrofaunal abundance and size-structure on the diet and growth of the western rock lobster Panulirus cygnus George. Journal of Experimental Marine Biology and Ecology 139, 1-22.

Gray, H. G. (1992). 'The western rock lobster. Book 1: A natural history.' (Westralian 285 Books: Geraldton.)

Haddon, M., and Wear, R. G. (1987). Biology of feeding in the New Zealand paddle crab Ovalipes catharus (Crustacea, Portunidae). New Zealand Journal of Marine and Freshwater Research 21, 55-64.

Hill, B. J. (1976). Natural food, foregut clearance-rate and activity of the crab Scylla serrata. Marine Biology 34, 109-116.

Jernakoff, P., Phillips, B. F., and Maller, R. A. (1987). A quantitative study of nocturnal 295 foraging distances of the western rock lobster Panulirus cygnus George. Journal of Experimental Marine Biology and Ecology 113, 9-21. 
Jernakoff, P., Phillips, B. F., and Fitzpatrick, J. J. (1993). The diet of post-puerulus western rock lobster, Panulirus cygnus George, at Seven Mile Beach, Western Australia. 300 Australian Journal of Marine and Freshwater Research 44, 649-655.

Jobling, M., and Davies, P. S. (1979). Gastric evacuation in plaice, Pleuronectes platessa L.: effects of temperature and meal size. Journal of Fish Biology 14, 539-546.

305 Joll, L. M. (1982). Foregut evacuation of four foods by the western rock lobster, Panulirus cygnus, in aquaria. Australian Journal of Marine and Freshwater Research 33, 939-943.

Joll, L. M., and Phillips, B. F. (1984). Natural diet and growth of juvenile western rock 310 lobster Panulirus cygnus George. Journal of Experimental Marine Biology and Ecology 75, 145-169.

Kanciruk, P., and Herrnkind, W. F. (1973). Preliminary investigations of the daily and seasonal locomotor activity rhythms of the spiny lobster, Panulirus argus. Marine 315 Behaviour and Physiology 1, 351-359.

Sarda, F., and Valladares, F. J. (1990). Gastric evacuation of different foods by Nephrops norvegicus (Crustacea: Decapoda) and estimation of soft tissue ingested, maximum food intake and cannibalism in captivity. Marine Biology 104, 25-30.

320

Williams, M. J. (1981). Methods for the analysis of natural diet in Portunid crabs (Crustacea: Decapoda: Portunidae). Journal of Experimental Marine Biology and Ecology 52, 103-113.

325 Zar, J. H. (1999). 'Biostatistical Analysis.' (Prentice-Hall International, Inc.: Sydney.) 


\section{Figure captions}

330

Fig. 1. Proportion of ingested food remaining in lobster foreguts for three different diet items fed to lobsters. Evacuation of diet items is modeled by exponential functions (solid line).

\section{Tables}

Table 1. Two way ANOVA for differences in proportion of ingested food remaining in lobster foreguts for lobsters fed different diets. Two factors design: diet (fixed, 3 levels) and time (fixed, 5 levels, crossed with diet).

\begin{tabular}{lccccc}
\hline Source of Variation & df & SS & MS & F-value & p-value \\
\hline Diet & 2 & 1.73 & 0.86 & 168.011 & $<0.001$ \\
Time & 4 & 0.44 & 0.11 & 21.209 & $<0.001$ \\
Diet $\times$ Time & 8 & 0.11 & 0.01 & 2.731 & 0.045 \\
Residual & 15 & 0.08 & 0.01 & & \\
Total & 29 & 2.53 & 0.08 & & \\
\hline
\end{tabular}

Table 2. One way ANOVA for comparison of amount of each diet type ingested by experimental lobsters during the feeding period.

\begin{tabular}{llllll}
\hline Source of Variation & df & SS & MS & F-value & p-value \\
\hline Diet type & 2 & 92.57 & 46.28 & 9.144 & $<0.001$ \\
Residual & 27 & 136.67 & 5.06 & & \\
Total & 29 & 229.24 & & & \\
\hline
\end{tabular}


345 